\section{As different as Venus and Mars: time to distinguish efficacy (can it work?) from effectiveness (does it work?)}

Karim M Khan, ${ }^{1}$ Hashel Al Tunaiji ${ }^{1}, 2$

Implementation. Knowledge Translation. Dissemination. Will these words dominate the 2010s the way 'evidence-based', 'systematic review' and 'Madonna' dominated the 1990s? At five diverse conferences in April and May 'implementation' was much more than a buzz. Responding to the zeitgeist, BJSM will focus on how research can move from the shelf (publication) to actually improve health outcomes (implementation). In the clinic, in the school, in the community. Personal and public health. Given that physical activity is arguably the most powerful public health solution, ${ }^{1}$ we need to embrace the public health domain of exercise medicine. Exercise is not only Medicine but also Public Health. Thanks to Professor Caroline Finch (Monash University and Twitter@CarolineFinch) for joining our Senior Associate Editorial Board to captain the implementation team (Think Dirk Nowitzki but even smarter). Listen to Caroline's keynote talk from the World Congress on Injury and Illness in Sport on the International Olympic Committee's (IOC) excellent website http://www.ioc-preventionconference.org/ (Online Presentations Icon). See her launch of BJSM's initiative on implementation in this issue (page 763).

One line summary? Examine the research cycle ${ }^{2}$ (figure 1) and move from steps 1-3 through to include 4-7. Teppo Jarvinen (concept) and Malcolm Willett (artist) combined to create this month's BJSM cover focus on steps 3-5 in particular. This was originally used in a $B M J$ analysis. $^{3}$

${ }^{1}$ Centre for Hip Health and Mobility \& Department of Family Practice, University of British Columbia, Vancouver, Canada

2Zayed Military Hospital, Abu Dhabi, United Arab Emirates

Correspondence to Dr Karim M Khan, Centre for Hip Health and Mobility \& Department of Family Practice, University of British Columbia, Vancouver V6T 1Z3,

Canada; karim.khan@ubc.ca

\section{'SMOKADIABESITY' - THE NEW EPIDEMIC}

Although the news has not yet hit the New England Journal of Medicine, there is an epidemic sweeping North America. You can read more about it on the BJSM blog (http://tiny.cc/00vmq) but it kills as many people in USA as do smoking, diabetes and obesity combined. NIH Nightmare. Yes, this worse-than-Ebola disease - smokadiabesity - kills a frightening 14\% of Americans. Fortunately, Professor Steven Blair had a premonition about this epidemic, so he already has 20-year prospective data comparing deaths from the new epidemic and from low fitness (figure 2). ${ }^{1}$ Astonishingly, low fitness still kills more Americans (16-18\%) than even rampant 'smokadiabesity'.
IN THIS ISSUE

Did I mention implementation? It's what will get folks moving for 22 minutes a day - to get everybody to walk! (www. everybodywalk.org). As well as Caroline Finch's editorial (see page 763), see Professor Adrian Bauman's powerful argument for velopalooza - cycling as a panacea (see page 761). Cheap green fun! Beware, however, the authors declaring their conflict in owning 15 bicycles. Robert Lamberts' paper (see page 797) on performance in cycling is timely as the Tour de France opens why was Lance Armstrong so much better than his contemporaries (oops! Bad example, the lawyers will need to review this now...).

Rolling right along with the cycling theme, it is appropriate that the Netherland Association of Sports Medicine (really De Vereniging voor Sportgeneeskunde (VSG)) has joined BJSM as a member society. All VSG physicians now have journal access through the VSG website. As a $B J S M$ member society, VSG guides one of the BJSM issues annually; readers will benefit from that in October. The Australian and New Zealand sport physicians are compiling the September issue. That month includes the bonus Injury Prevention and Health Promotion (IPHP)

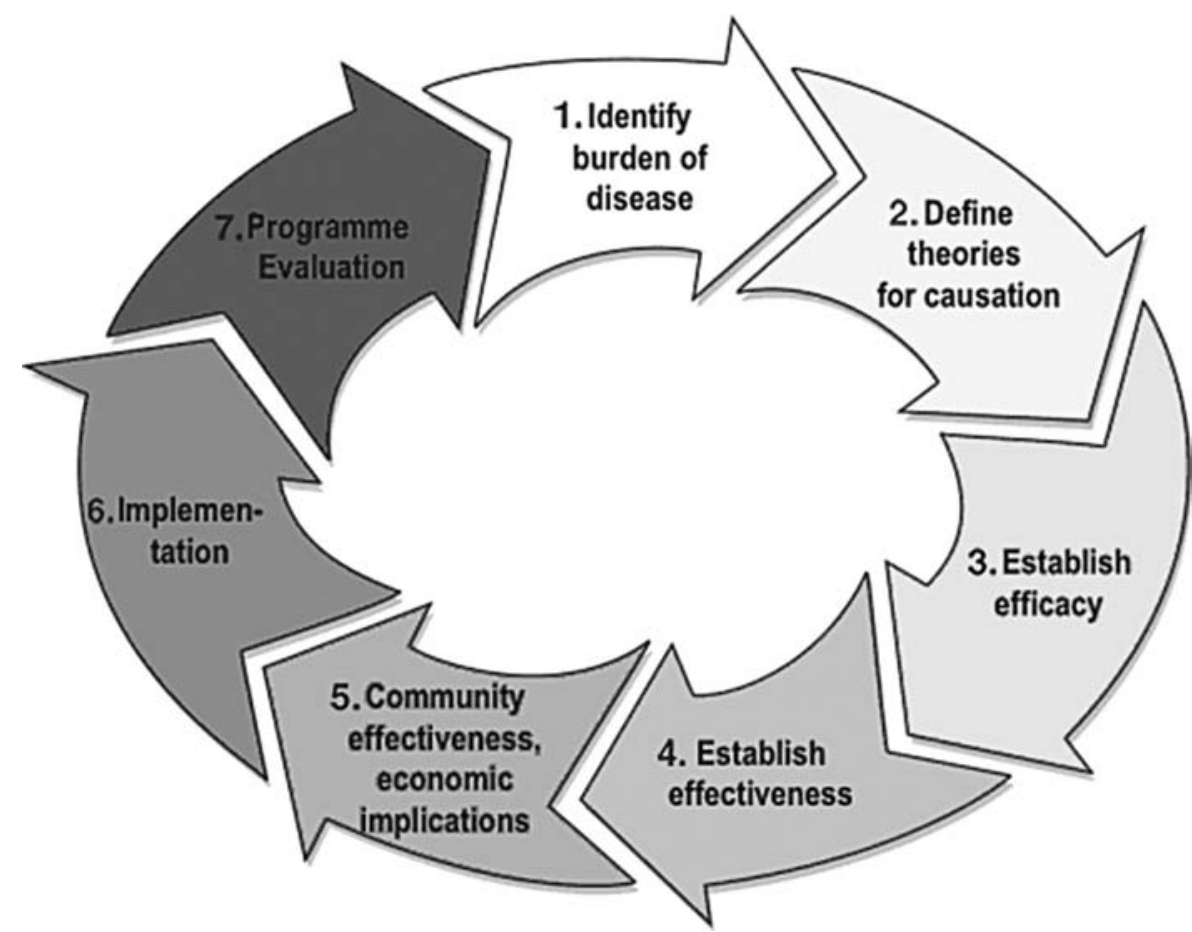

Figure 1 The research cycle. ${ }^{2}$ In this model, there are seven distinct steps. The first is identifying the burden of disease and the seventh is evaluating a programme that provides health benefits in the real world (eg, a prevention program for sports injuries). 


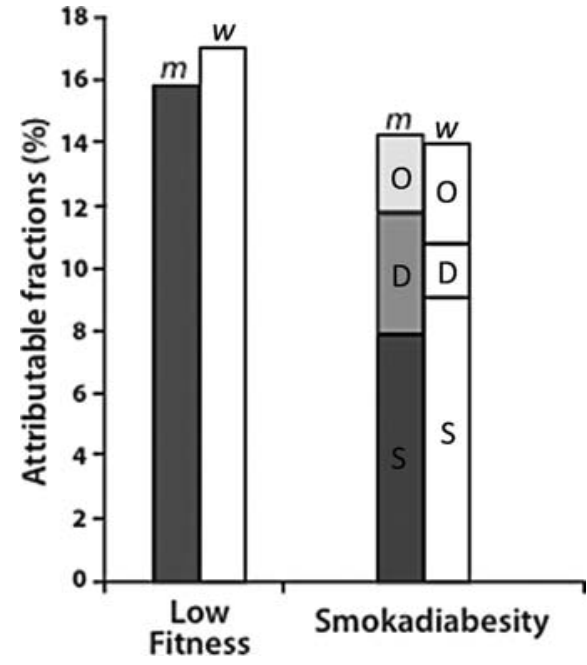

Figure 2 A comparison of deaths attributable to low fitness (men (m) and women (w)) and the combined effect of smoking (S), diabetes (D) and obesity (O) (men and women). Slide represents the identical data published by Blair (2009). ${ }^{1}$ issue which addresses Children and Sport (BJSM provides 16 issue a year!). This terrific issue came of an IOC initiative to invite global leaders to Lausanne for a workshop in February of 2011. The key message? Time to implement what we already know about children and sport.

The year closes with November's AMSSM (The American Medical Society for Sports Medicine) issue, December's hamstring-focussed ECOSEP (European College of Sports and Exercise Physicians) issue as well as the IPHP issue on Youth Sport Olympics.

In closing this month, beware the smokadiabesity, but if you are an unwitting victim of it, remember that 22 minutes of physical activity daily could prevent even more deaths in America. Time for all clinicians to try to get that behaviour to be widespread. ${ }^{4}$ Time to step up Archie Cochrane's ladder (cover image) and crank the research cycle (figure 1) all the way around.
Competing interests None.

Provenance and peer review Commissioned; internally peer reviewed.

Accepted 20 June 2011

Br J Sports Med 2011:45:759-760.

doi:10.1136/bjsports-2011-090334

\section{REFERENCES}

1. Blair SN. Physical inactivity: the biggest public health problem of the $21^{\text {st }}$ century. Br J Sports Med 2009;43:1-2.

2. Tugwell P, Bennett KJ, Sackett DL et al. The measurement iterative loop: a framework for the critical appraisal of need, benefits and costs of health interventions. J Chronic Dis 1985:38:339-51.

3. Jarvinen TL, Sievanen $\mathrm{H}$, Kannus P, et al. The true cost of pharmacological disease prevention. BMJ 2011;342:d2175.

4. Khan KM, Weiler, R, Blair SN. Prescribing exercise in primary care. Seven practical steps on how to do it. BMJ 2011;343:d4141. 